\title{
Testing the Purchasing Power Parity Theory: A Case of the Taiwanese Dollar Exchange Rate
}

\author{
Hiroki Tsurumi \\ Rutgers University \\ Chyong L. Chen \\ Feng Chia University
}

\begin{abstract}
From July 1978 to April 1989 Taiwan adopted a snake system by allowing the foreign exchange rate to fluctuate within a narrow band of the centered rate. Using monthly data on the Taiwan dollar/U.S. dollar exchange rate, we show that inference on the purchasing power parity hypothesis is sensitive to whether we incorporate double truncation and autoregressive and moving average er ror terms into the regression model. (JEL Classification: C2, F4)
\end{abstract}

\section{Introduction}

The purchasing power parity (PPP) theory has been put to empirical tests many times. In this paper we present a Bayesian test of the PPP theory 
using data on the Taiwanese dollar/ U.S. dollar exchange rate.

After the collapse of the Bretton Woods system in 1973, foreign exchange rates of many countries were floated within upper and lower bounds. Well known examples are some European currencies and a less known case is the Taiwanese version of the snake system. What will happen to the test of the PPP theory if we incorporate the information that the foreign exchange rate time series experienced double truncation? Using monthly data on the

Taiwanese-dollar/ U.S.-dollar exchange rate, we show that inference on the PPP hypothesis is sensitive to whether we incorporate double truncation and ARM A error terms into the regression model.

The organization of the paper is as follows. In section II we present an account of the experience of the Taiwan dollar exchange rate since 1973, and in section III we present the conventional tests of the PPP theory. In section IV we present the Bayesian test. Concluding remarks are in section V. In Appendix we derive the Bayesian posterior probability density functions ( $p d f$ 's) of the relevant parameters of the regression model.

\section{The Experience of the Taiwan Dollar Exchange Rate since 1973}

The Bretton Woods system collapsed in the early spring of 1973. While the currencies of J apan and most E uropean countries were floated against the U.S. dollar, many developing countries continued to peg to the dollar, and Taiwan was not an exception. It maintained the fixed exchange rate until early July 1978. From February 1979 to April 1989, Taiwan formally adopted its own "snake" system by allowing the exchange rate to fluctuate within a narrow band of the centered rate. At first the centered rate was determined by the Exchange Rate Decision Committee whose members consisted of the representatives from the central bank and five major banks 
Figure 1

NT Dollar Exchange Rate Per U.S. Dollar

(1973.01- 1992.12)

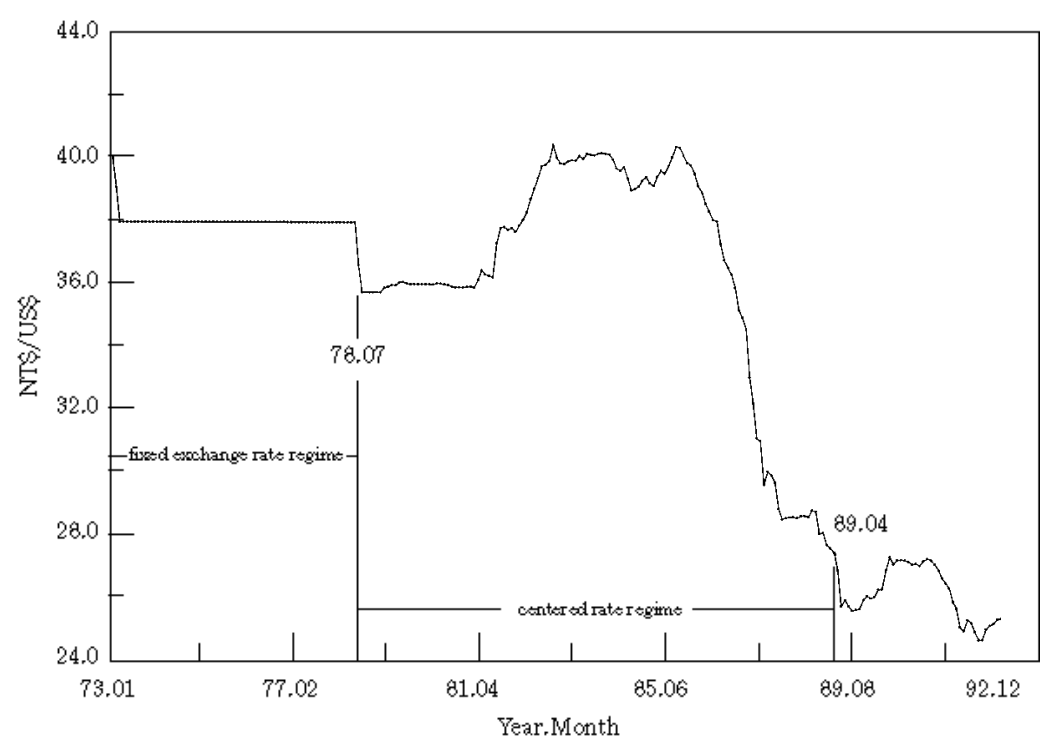

more or less around a new constant level until November 1985, right after the Plaza accord. The fluctuations of NT dollar from 1981 to 1985 were wider than those before J uly 1981. After the Plaza accord in the fall of 1985 , NT dollar started to appreciate rapidly just as yen and Deutsche mark did. The allowable band of the fluctuation of the NT dollar rate was first set at $\pm 0.5 \%$ of the centered rate at the beginning of the system, and then was widened to $\pm 2.25 \%$ on August 121981 . Since April 1989, the government has let the NT dollar rate be determined in the market. The market, however, has not been totally free of control, although beginning in 1986 the exchange control measures began to be lifted rapidly. In Appendix A a chronological summary of the centered rate system and the NT dollar exchange 


\section{Figure 2}

Volume of Foreign Currency Transactions between

$B$ anks and Non-B ank Customers

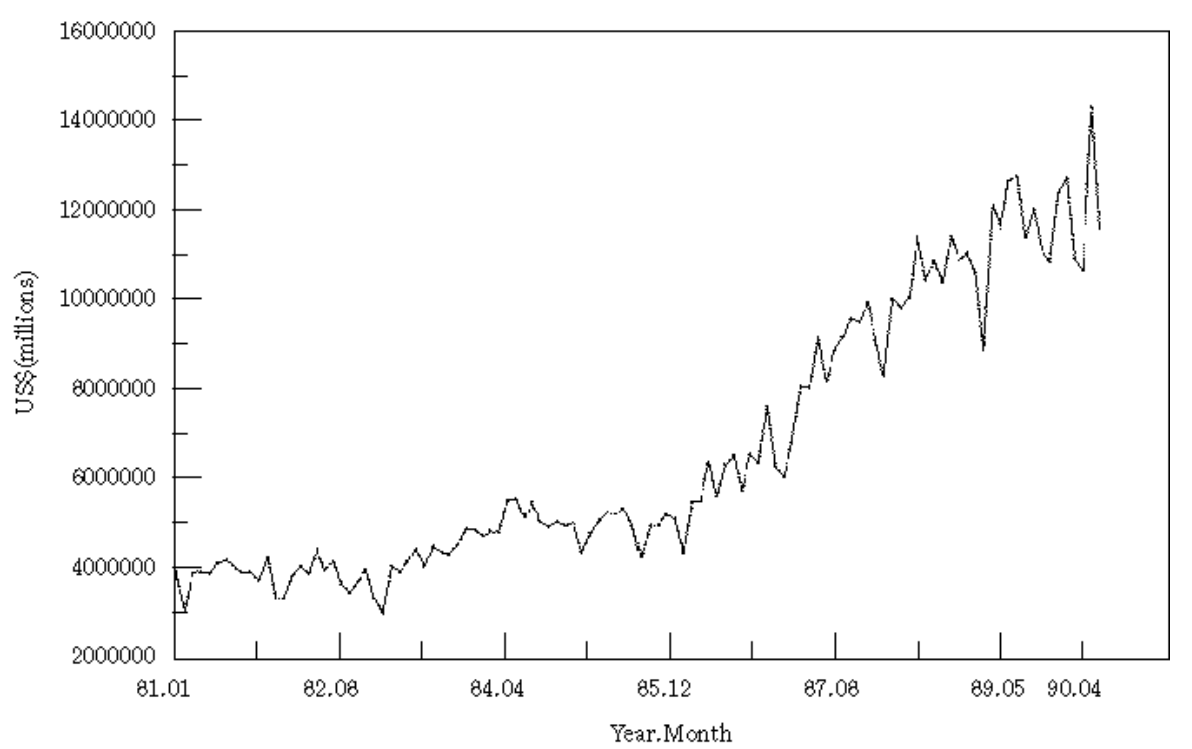

bank customers from 1981 to 1990 were presented. As the foreign exchange market in Taiwan expanded and its economy became more open and linked to the global economy, the foreign exchange manipulation by the central authority became more and more difficult.

\section{Conventional Tests of the Purchasing Power Parity Theory: the Taiwan/U.S. Dollar Exchange Rates}

The purchasing power parity (PPP) theory has been tested extensively in recent vears. The relative PPP is expressed bv 
Model 1: $\quad r_{t}=+r_{t-1}+u_{t}$

where $r_{t}=E_{t} P_{t}^{*} / P_{t}$. Asserting that the PPP is a long-run relationship, the test of the PPP by model 1 is to test whether $\rho$ is one or not, since if $\rho=1$ then $r_{t}$ is a random walk without any tendency to fluctuate around $\alpha /(1-\rho)$. Taking the logarithm of equation (1) and adding the er ror term, we have

$$
\text { Model 2: } \quad \ln \mathrm{E}_{\mathrm{t}}=+\left(\ln \mathrm{P}_{\mathrm{t}}-\ln \mathrm{P}_{1}^{*}\right)+\mathrm{U}_{\mathrm{t}}
$$

and we may say that the PPP holds if $\beta=1$. This test of the PPP hypothesis is a test of a regression coefficient. M odel 3 is to modify model 2 :

$$
\text { Model 3: } \quad \ln \mathrm{E}_{\mathrm{t}}=+\ln \mathrm{P}_{\mathrm{t}}-{ }_{2} \ln \mathrm{P}_{1}^{*}+\mathrm{U}_{\mathrm{t}}
$$

and test the simultaneous restriction on the coefficients: $\left(\beta_{1}, \beta_{2}\right)=(1,-1)$. In models 2 and 3 , one may also test whether a cointegrating relationship holds among the regressand and regressors.

There is no consensus on which price indexes, wholesale or consumer prices, should be used, and also the choice of the foreign currency (or base country cur rency) varies from one study to another. Table 1 presents a summary of the literature since 1988, highlighting data, years under study, base country, price indexes, models, test methods and findings. All of these studies treat that the time series data on the exchange rates are free of truncation.

Let us test the PPP theory for the NT dollar exchange rate using all of the three models. First we tested whether the time series data that are relevant to the PPP hypothesis have a unit root. We use the augmented DickeyFuller test (ADFT) as well as the augmented point optimal test (APOT). The APOT test is proposed by Nakatsuma, Uemura, and Tsurumi [1997], and it tends to have better powers than the ADFT. At the $5 \%$ significance level all 
Table 1

Tests of PPP : A Quick Survey of the Literature

\begin{tabular}{|c|c|c|c|c|c|c|c|}
\hline Authors & $\begin{array}{l}\text { data } \\
\text { type }\end{array}$ & years & $\begin{array}{c}\text { base } \\
\text { country }\end{array}$ & $\begin{array}{l}\text { price } \\
\text { index }\end{array}$ & model & $\begin{array}{l}\text { test } \\
\text { method }\end{array}$ & conclusions \\
\hline $\begin{array}{l}\text { Corbae and } \\
\text { Ouliaris } \\
\text { [1988] }\end{array}$ & month & $73.07-86.09$ & U.S. & CPI & 2 & $A D F, P P$ & $\begin{array}{l}\text { PPP does not hold, } \\
\text { no cointegration }\end{array}$ \\
\hline $\begin{array}{l}\text { Enders } \\
\text { [1988] }\end{array}$ & month & $\begin{array}{l}60.04-71.05 \\
73.01-86.11\end{array}$ & U.S. & WPI & 1 & $\begin{array}{l}\text { ARIMA, } \\
\text { DF }\end{array}$ & $\begin{array}{l}\text { PPP does not hold } \\
\text { during the flexible } \\
\text { rate regime. }\end{array}$ \\
\hline $\begin{array}{l}\text { Abuaf and } \\
\text { Jorion } \\
\text { [1990] }\end{array}$ & month & $73.01-87.12$ & U.S. & $\mathrm{CPI}$ & 1 & $\begin{array}{l}\mathrm{ARCH} \\
\mathrm{GLS}, \mathrm{DF}\end{array}$ & PPP holds. \\
\hline $\begin{array}{l}\text { Corbae and } \\
\text { Ouliaris } \\
\text { [1990] }\end{array}$ & annual & 1890-1984 & $\begin{array}{l}\text { Austra- } \\
\text { lia }\end{array}$ & $\begin{array}{l}\text { WPI } \\
\text { CPI }\end{array}$ & 1 & $\begin{array}{l}\text { ADF } \\
\text { str.break }\end{array}$ & PPP does not hold. \\
\hline Kim [1990] & quarter & $\begin{array}{l}1900-87 \\
1914-87\end{array}$ & U.S. & PPI & 2 & $\begin{array}{l}\text { PP, ADF, } \\
\text { Johansen, } \\
\text { SW }\end{array}$ & $\begin{array}{l}\text { PPP and coint hold } \\
\text { in general. }\end{array}$ \\
\hline Patel [1990] & qiarter & $1974-86$ & U.S. & PPI & 3 & ADF, SW & $\begin{array}{l}\text { PPP holds at most } \\
4 \text { of } 5 \text { country pairs. }\end{array}$ \\
\hline $\begin{array}{l}\text { Taylor } \\
\text { [1990] }\end{array}$ & month & $73.03-85.12$ & U.S. & $\begin{array}{l}\text { WPI } \\
\text { CPI }\end{array}$ & 2 & $\begin{array}{l}\text { Wald, } \\
\text { ARCH }\end{array}$ & $\begin{array}{l}\text { Ex-ante PPP holds } \\
\text { in the VAR setting. }\end{array}$ \\
\hline $\begin{array}{l}\text { Perron and } \\
\text { Vogelsang } \\
\text { [1992] }\end{array}$ & annual & $\begin{array}{l}1892-1988 \\
1869-1987\end{array}$ & $\begin{array}{l}\text { US/ UK } \\
\text { US/ Fin }\end{array}$ & $\begin{array}{l}\text { CPI } \\
\text { GNP }\end{array}$ & 1 & str.break & $\begin{array}{l}\text { PPP holds if } \\
\text { structural breaks } \\
\text { are considered. }\end{array}$ \\
\hline $\begin{array}{l}\text { Tronzano } \\
\text { [1992] }\end{array}$ & quarter & $55.01-90.02$ & $\begin{array}{l}\text { US } \\
\text { DM }\end{array}$ & $\mathrm{CPI}$ & $\begin{array}{l}1 \\
3\end{array}$ & $\begin{array}{l}\text { ADF, LR } \\
\text { CRDW, } \\
\text { VR }\end{array}$ & $\begin{array}{l}\text { PPP does not hold } \\
\text { for DM / US and } \\
\text { Yen/ US but holds } \\
\text { for Yen/ DM }\end{array}$ \\
\hline $\begin{array}{l}\text { Cheung and } \\
\text { Lai [1993] }\end{array}$ & month & $74.01-89.12$ & US & $\begin{array}{l}\text { WPI } \\
\text { CPI }\end{array}$ & 3 & $\begin{array}{l}\text { ADF, PZ, } \\
\text { Johansen }\end{array}$ & PPP holds. \\
\hline Flynn and & month & $63.01-70.05$ & US & $\mathrm{CPI}$ & 1 & $P, D F$ & PPP does not hold. \\
\hline
\end{tabular}

Notes: $D F=D$ i c k e y Fuller test; ADF =Augmented DF test; $\mathrm{LR}=\mathrm{L}$ agrange multiplier test; CRDW =co-integration test by Durbin-Watson test; VR=vari ance ratio test; $P P=P$ hillips and Perron tests; $\mathrm{PZ}=\mathrm{Phillips} \mathrm{Z}$ test; WPI, CPI, $\mathrm{PPI}, \mathrm{GNP}=$ wholesale, consumer, producer and GNP price indices.; Johansen= oha nsen's cointegration test; $\mathrm{SW}=$ Stock-W atson test; W a l d =W a ld test; $P=$ Perron's test. 
Table 2

Unit Root Tests for the Variables for the PPP Hypothesis

\begin{tabular}{|l|c|c|}
\hline \multicolumn{1}{|c|}{ Variable } & ADFT & APOT (p-value) \\
\hline E.(CPIUS/ CPITWN) & -2.0792 & $.9963(.583)$ \\
\hline E.(WPIUS/ WPITWN) & -2.4197 & $.9962(.403)$ \\
\hline $\ln E$ & -2.3083 & $.9956(.565)$ \\
\hline $\ln ($ CPITWN/ CPIUS) & -2.1210 & $.9891(.403)$ \\
\hline $\ln ($ WPITWN/ WPIUS) & -2.9962 & $.9890(.402)$ \\
\hline $\ln ($ CPITWN) & -2.2370 & $.9852(.313)$ \\
\hline $\ln ($ CPIUS) & $-3.7030^{*}$ & $.9838(.279)$ \\
\hline $\ln ($ WPITWN) & -2.9963 & $.9704(.029)$ \\
\hline $\ln$ (WPIUS) & -2.3849 & $.9784(.159)$ \\
\hline
\end{tabular}

Notes: ADFT = augmented Dickey-Fuller test, computed with 6 lags;

APOT $=$ augmented point optimal test, computed with 6 lags;

$E=N T \$ /$ US $\$$ spot exchange rate;

$\mathrm{CPI}_{j}=$ consumer price index of country $\mathrm{j}$, $(\mathrm{j}=\mathrm{TWN}$, for Taiwan $\mathrm{j}=\mathrm{US}$ for U.S.)

$W \mathrm{PI}_{j}=$ wholesale price index of country $j$;

The $5 \%$ critical value of the ADFT is -3.437 . (* indicates significance at the $5 \%$ level.)

The prob-values of the APOT are based on 5,000 replications of the null distribution.

\section{Table 3}

\section{Testing the PPP by Model 2'}

Dependent Variable is $\Delta \mathrm{lnE}$

\begin{tabular}{|l|c|l|c|}
\hline constant & $\begin{array}{c}-.0015 \\
(.0025)\end{array}$ & constant & $\begin{array}{c}-.0011 \\
(.0024)\end{array}$ \\
\hline$\Delta \ln$ CPITWN/ CPIUS & $\begin{array}{c}-.0122 \\
(.0329)\end{array}$ & $\Delta$ In WPITWN/ WPIUS & $\begin{array}{c}.1108 \\
(.0381)\end{array}$ \\
\hline$\Delta R(1)$ & .7855 & $\Delta R(1)$ & .7809 \\
\hline
\end{tabular}


Table 4

Testing the PPP by Model 3'

Dependent Variable $=\Delta \ln E$

\begin{tabular}{|l|l|l|c|}
\hline Constant & $\begin{array}{l}-.0008 \\
(.0025)\end{array}$ & Constant & $\begin{array}{c}-.0017 \\
(.0026)\end{array}$ \\
\hline \multirow{2}{*}{$\Delta$ In CPITWN } & -.0136 & $\Delta$ In WPITWN & .1360 \\
& $(.0334)$ & & $(.0449)$ \\
\hline \multirow{2}{*}{$\Delta$ In CPIUS } & -.0694 & $\Delta$ In WPIUS & -.0066 \\
& $(.1855)$ & & $(.0607)$ \\
\hline \multirow{2}{*}{$\mathrm{AR}(1)$} & .7611 & $\mathrm{AR}(1)$ & .7937 \\
& $(.2034)$ & & $(.1807)$ \\
\hline \multirow{2}{*}{$\mathrm{M} \mathrm{A}(1)$} & -.4875 & $\mathrm{MA}(1)$ & -.5407 \\
& $(.2005)$ & & $(.1707)$ \\
\hline $\mathrm{F} \mathrm{statistic}$ & 360.14 & $\mathrm{~F} \mathrm{statistic}$ & 243.90 \\
\hline
\end{tabular}

Notes: The selection of $\operatorname{ARM} A(1,1)$ processes is based on the Akaike information criterion as well as on the Box-Pierce test.

The figures in parentheses are estimated standard errors.

The $F$ statistics are for testing the null hypothesis of $\left(\beta_{1}, \beta_{2}\right)=(1,-1)$.

The null hypothesis is clearly rejected in both cases.

difference the variables and run regression on

$$
\text { Model 2': } \quad \Delta \ln E_{\mathrm{t}}=+\Delta \ln \left(\mathrm{P}_{\mathrm{t}} / \mathrm{P}_{\mathrm{t}}^{*}\right)+{ }_{\mathrm{t}}
$$

and on

$$
\text { Model 3': } \quad \Delta \ln E_{\mathrm{t}}={ }_{1} \ln \mathrm{P}_{\mathrm{t}}+{ }_{2} \ln \mathrm{P}_{\mathrm{t}}^{*}+{ }_{\mathrm{t}}
$$

where is a stationary process, and the differenced series are stationary. The regression results and the $F$ test statistics for testing $\left(\beta_{1}, \beta_{2}\right)=(1,-1)$ are pre- 
"snake" from July 1978 to April 1989. This means that the time series $\left\{E_{t}\right\}$ fluctuated within upper and lower bounds during this period, and we may formalize the doubly truncated series as

$$
\left\{\begin{array}{cll}
\text { low }_{t} \leq E_{t} \leq u_{t} & t=1978.07, & , 1989.04 \\
E_{t} \text { is unconstrained } t=1989.05, & , 1992.12
\end{array}\right\}
$$

where $E_{t}$ is the Taiwan dollar per U.S. dollar at time t, and $\operatorname{low}_{t}$ and $u p_{t}$ are lower and upper bounds at time $t$, respectively.

In the previous section we said that the Taiwanese authority allowed the $N T$ dollar rate, $E_{t}$, to stay within narrow bands of the centered rate, $C_{t}$. If data on $\mathrm{C}_{\mathrm{t}}$ and on the bands were available, we could compute the lower and upper bounds $\operatorname{low}_{t}$ and $\mathrm{up}_{\mathrm{t}}$. Since these data are not available, we need to construct the bounds. It is generally known that the Taiwanese authority wanted to maintain the exchange rate at a cor stant level.

Examining Figure 1 and various central bonk reports, we identify three regimes: 1978.07-1981.07, 1981.08-1985.10 and 1985.11-1989.04. For the period of 1978.07-1981.07, stayed virtually constant at $E_{t}=36.0$. This implies that $E_{t}$ was ver $y$ close to $C_{t}$ during this period and we may safely put

$$
1_{1}^{*} \leq E_{t} \leq U_{1}^{*} \text { for } 1978.07-1981.07
$$

where $\ell_{1^{*}}=\min \left(E_{t}\right)$ and $u_{1}^{*}=\max \left(E_{t}\right)$ for regime 1 of $t=1978.07, \ldots, 1981.07$.

From 1981.08, when the government depreciated the exchange rate from 36.24 to 38 , to the Plaza accord in 1985.10, $E_{t}$ fluctuated more widely than the previous period around a new constant level of $E_{t}=39.25$ and we may set

$$
2_{2^{*}} \leq E_{t} \leq u_{2}^{*} \text { for } 1981.08-1985.10
$$

where $\ell_{2^{*}}=\min \left(E_{t}\right)$ and $u_{2}^{*}=\max \left(E_{t}\right)$ for regime 2 of $t=1981.05, \ldots, 1985.10$.

After the Plaza accord, $E_{+}$started to appreciate steadilv. If we take the 
than the constant bounds, we may argue that the bounds were based on the previous values of the NT/ US dollar exchange rate, and set the bounds as follows:

$$
\begin{aligned}
& \left(1-r_{1}\right) E_{t-1} \leq E_{t} \leq\left(1+r_{1}\right) E_{t-1}, \quad r_{1}=\max \left(\Delta E_{t} \mid / E_{t-1}\right), \text { for } t=1978.07-1981.07 \\
& \left(1-r_{2}\right) E_{t-1} \leq E_{t} \leq\left(1+r_{2}\right) E_{t-1}, \quad r_{2}=\max \left(\Delta E_{t} \mid / E_{t-1}\right), \text { for } t=1981.08-1985.10 \\
& \left(1-r_{3}\right) E_{t-1} \leq E_{t} \leq\left(1+r_{3}\right) E_{t-1}, \quad r_{3}=\max \left(\Delta E_{t} \mid / E_{t-1}\right), \text { for } t=1985.11-1989.04
\end{aligned}
$$

Figure 4 presents the alternate bounds. The bounds in the first two regimes in Figures 3 and 4 are fairly similar, whereas the bounds in Figure 4 for regime 3 are much tighter than those in Figure 3.

Given these bounds either in Figure 3 or in Figure 4, let us test the PPP theory using M odel 2.

$$
s_{t}=+p_{t}+u_{1}
$$

where $s_{t}=\ln \left(E_{t}\right)$ is

$$
\begin{cases}\ln (\text { low }) \leq s_{t} \leq \ln \left(\text { up }_{t}\right), \text { for } t=1978.07, & , 1989.04 \\ s_{t} \text { is unconstrained, for } t=1989.05, & , 1992.12\end{cases}
$$

and $u_{\mathrm{t}}$ is given by

$$
u_{t}=\frac{\Theta(B)}{(1-) \Phi(B)}
$$

and $\Theta(B)$ and $\Phi(B)$ are polynomials in the backward shift operator $B$. We wish to test whether $\beta$ is one or not. The variable $p_{t}$ in equation (2) is natural logarithm of the ratio of the Taiwan price to the U.S. price. As the price variables, we use the wholesale as well as consumer price indices. In Appendix $B$ we derive the posterior probability density functions ( $p d f$ 's) for $\beta$ as well 
Figure 3

\section{Log of NT\$/US\$}

(1978.07- 1992.12)

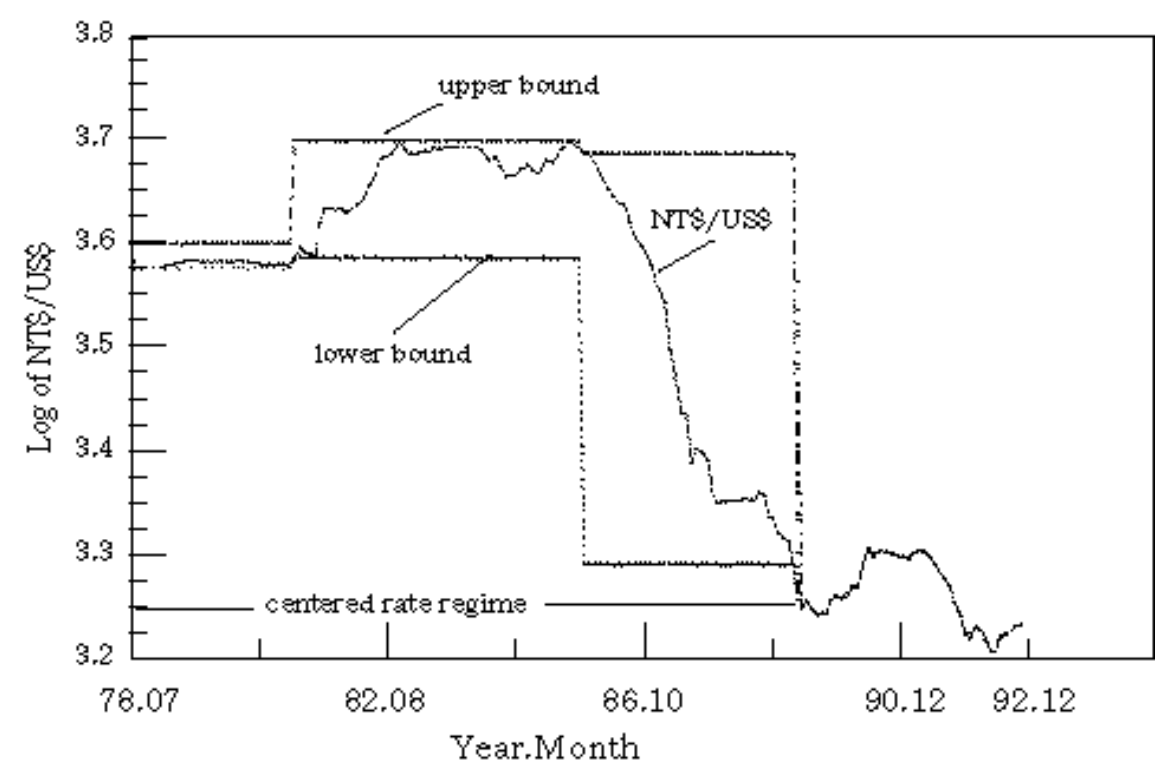

Figure 4

Log of NT\$ / US\$

(1978.07- 1992.12, Alternate B ounds)

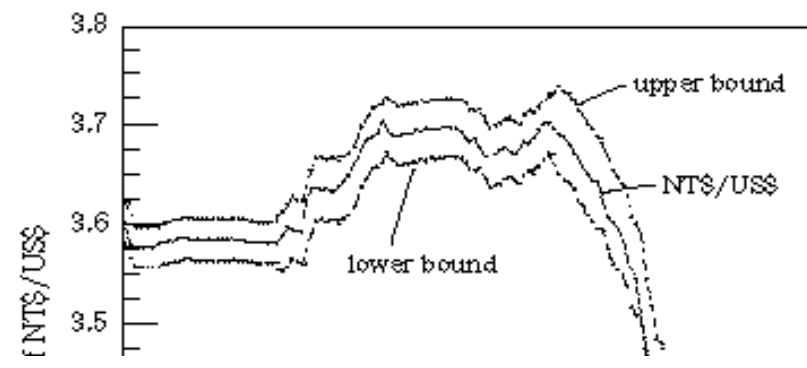




\section{Figure 5}

Posterior Pdf's of B eta under Different B ounds (Using WPI)

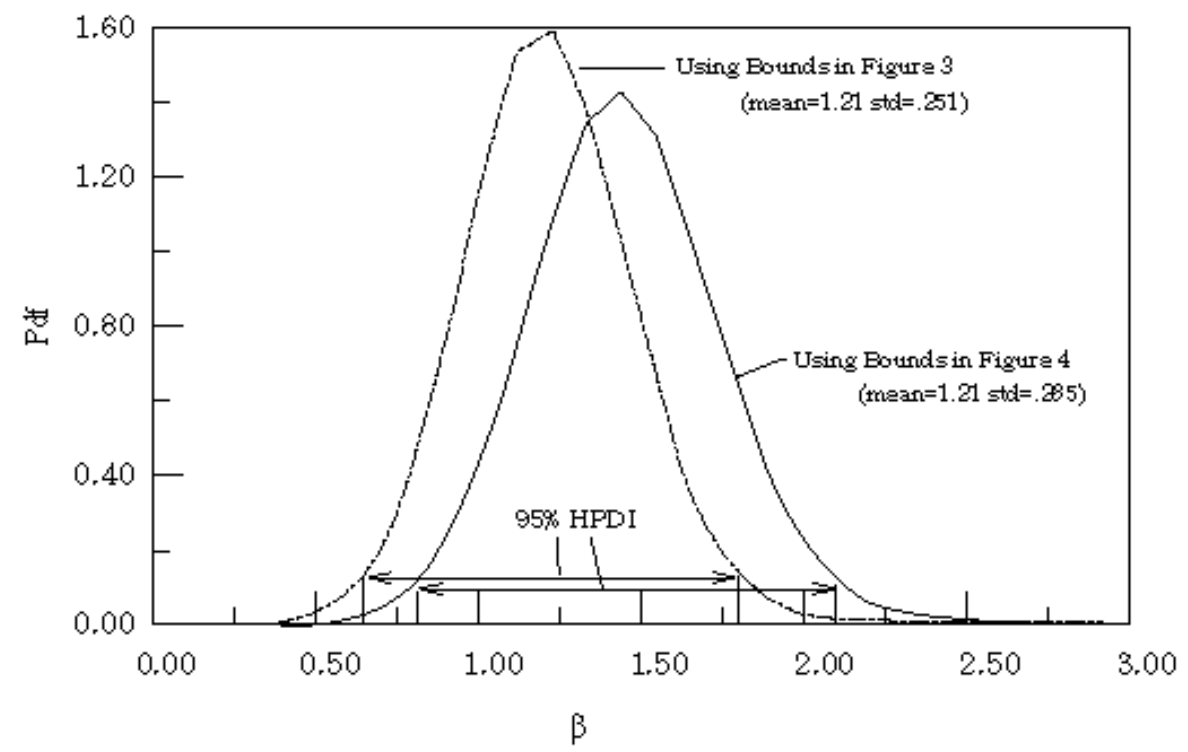

Figure 6

Posterior Pdf's of B eta under Different B ounds (Using CPI)

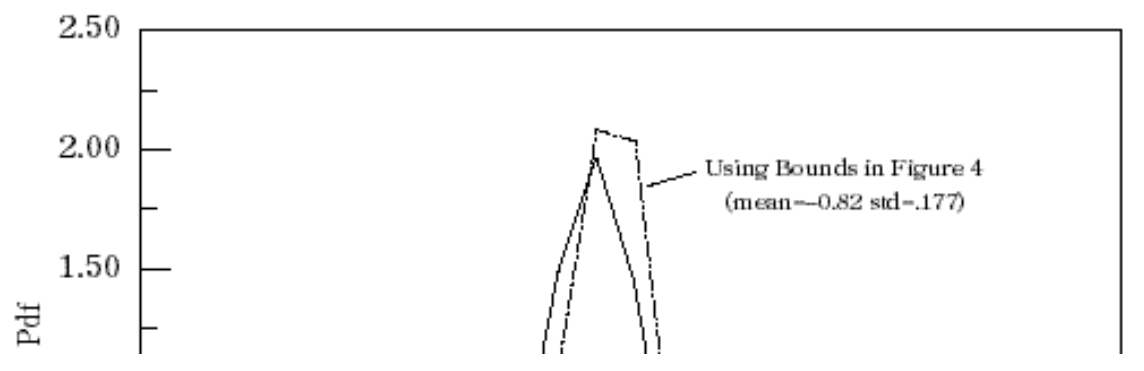


From Figures 5 and 6 we observe

(1) The 95\%HPDI's for $\beta$ using the wholesale price indices (WPI) contain $\beta=1$ whether we use the bounds in Figure 3 or the bounds in Figure 4.

(2) The posterior pdf's for $\beta$ using the consumer price indices (CPI) are centered around $\beta=1$ whether we use the bounds in Figure 3 or the bounds in Figure 4.

(3) The posterior pdf's for $\beta$ shift as the bounds for truncation change, but the finding that $\beta=1$ if we use the WPI but $\beta \neq 1$ if we use the CPI does not change with the choice of the bounds.

Figures 7 and 8 present, respectively, the posterior pdf's for $\rho$ and for $\sigma$. Since the posterior pdf's are similar whether we use the WPI or CPI as the price variable, we present the posterior pdf's using the WPI. The posterior means and standard deviations are shown in the figures. The hypothesis of a unit root $(\rho=1)$ is clearly supported.

If we take the position that the PPP theory is the relationship between the

Figure 7

Posterior Pdf's of Rho under Different Bounds (WPI)

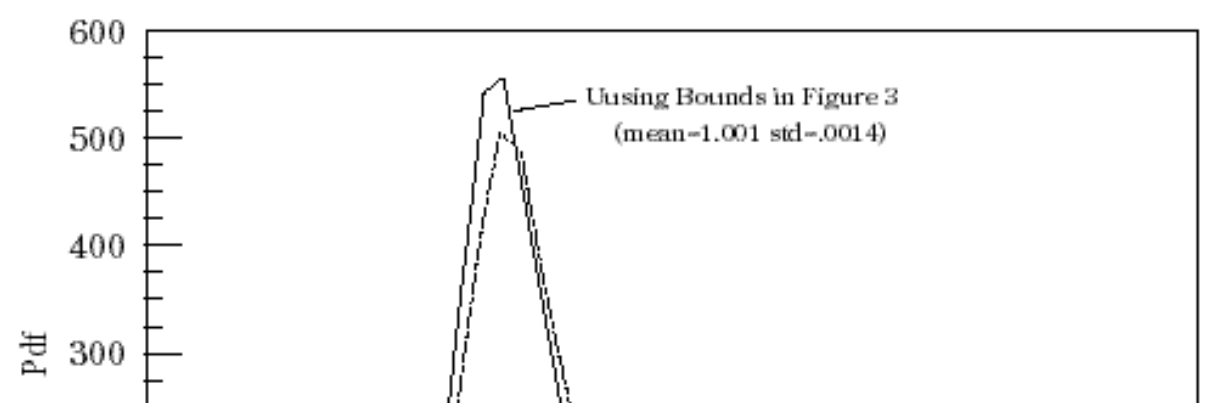




\section{Figure 8}

\section{Posterior Pdf's of Sigma under Different B ounds (WPI)}

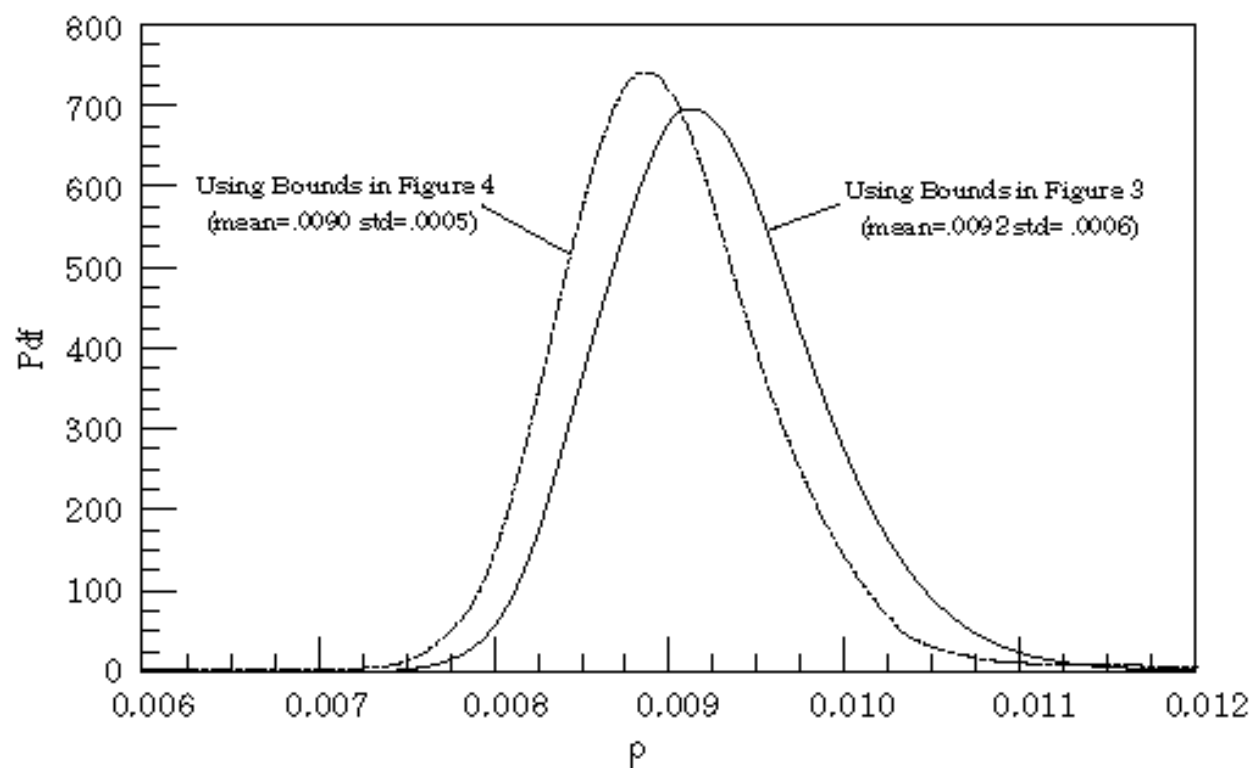

exchange rate and the relative prices of the two countries, then the PPP theory is tested by whether $\beta=1$ or not. However, we may argue that the premise of the PPP theory is the existence of a long-run equilibrium relationship and such a relationship excludes the possibility of a random walk. Then an appropriate test of the PPP theory is a joint test of $\beta=1$ and $|\rho|<1$ (or the joint test that $\beta=1$ and a cointegrating relationship exists.)

The issue on whether the PPP theory is premised upon the cointegrating relationship needs to be carefully researched and evaluated. If we take the position that it is not, then we can say that when the double truncation of the time series on the exchange rate is incorporated in the Bayesian analy- 


\section{Figure 9}

\section{NT\$/ US\$, Relative WPI and CPI}

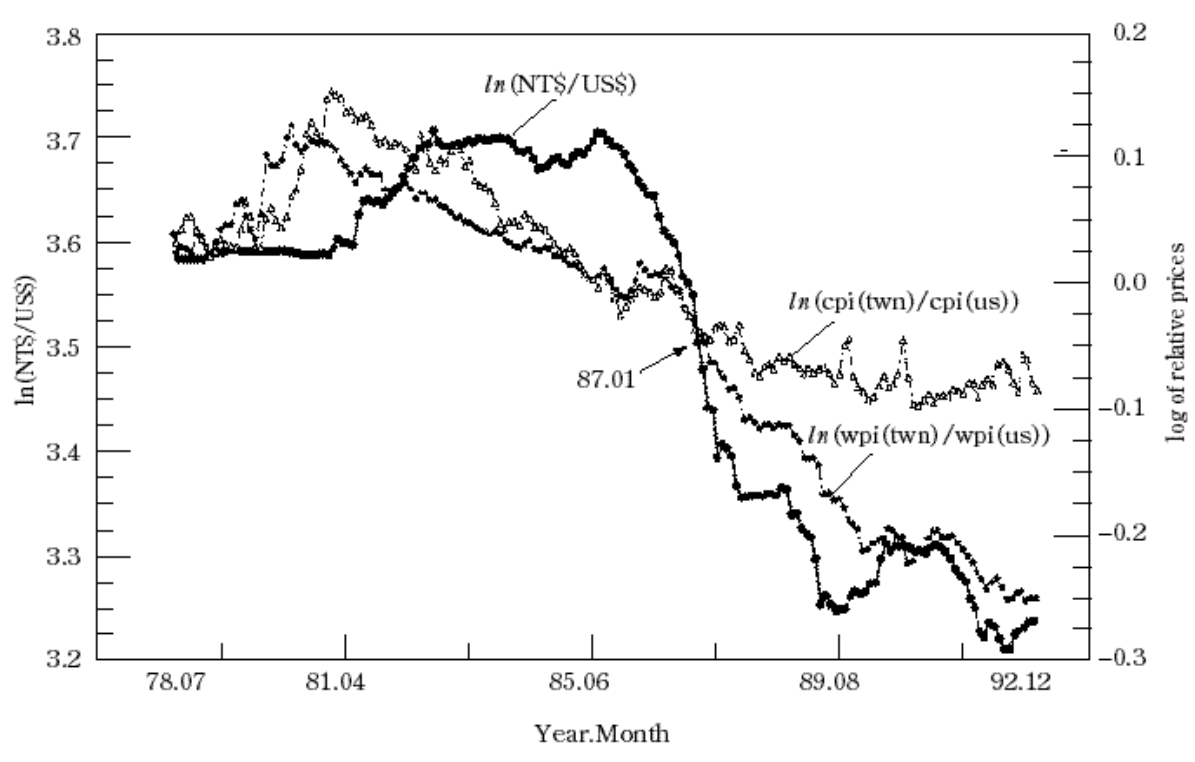

series showed similar movements but from $1987.02 \ln ($ WPITWN )/ WPIUS) kept declining while $\operatorname{In}($ CPITWN)/CPIUS) stayed constant. This is shown in Figure 9.

The reason why WPITWN/WPIUS kept falling in conjunction with the appreciation of the exchange rate is because the Taiwanese wholesale price index, WPITWN declined at the annual rate of $1.2 \%$ while the U.S. wholesale price index, WPIUS, increased $2.6 \%$ per year. The Taiwanese and U.S. consumer price indices, CPITWN and CPIUS, increased annually at $3.0 \%$ and 4.0\% respectively during 1987.02-1992.12.

The rapid appreciation of the Taiwanese dollar exchange rate since the 
consumer price indices.

The reasons why the CPI of Taiwan increased may be debated, but we may point out two factors that kept the CPI from falling: the rapid increase in the per capita income in Taiwan that pushed demand for consumer goods high and the existence of various regulations, or what may be called the structural impediments, that impeded competition in the consumer sector. The Taiwanese economy has begun to be more open and competitive, and it is possible that in the future we may see that the PPP theory may be supported by the use of the consumer price indices.

\section{Concluding Remarks}

In this paper we have found that the PPP theory does not hold for the Taiwanese dollar exchange rate if we use the use the conventional tests that ignore the double truncation of the time series on the exchange rate. If we incorporate it, however, the PPP theory holds for the wholesale price indices but not for the consumer price indices. We have used the Bayesian inference procedure for the doubly truncated regression model.

\section{References}

Abuaf, N., and Jorion P. [1990], "Purchasing Power Parity in the Long Run," Journal of Finance 145(1); pp. 157-74.

Central Bank of China, Annual Reports, Taipei, Taiwan, Various Issues.

Chen, L. C. [1996], "Detecting Structural Shift Points for NT Dollar: Japanese $Y$ en and German M ark by Bayesian Approach," N ational Council Research Paper, No. NSC 85-2415-H-035-013, Taipei Taiwan.

Cheng, Y.W. and Lai, K.S. [1993a], "A Fractional Cointegration Analysis of 
Corbae, D. and Ouliaris, S. [1990], "A Test of Long-Run Purchasing Power Parity Allowing for Structural Breaks," E conomic Record 66; pp. 488-501.

Davidson, J. [1994], Stochastic Limit Theory, Oxford: Oxford University Press.

Enders, W. [1988], "ARIM A and Cointegration Tests of PPP under Fixed and Flexible Exchange Rate Regimes," Review of Economics and Statis tics 70; pp. 504-08.

Flynn, N. A. and B oucher J . L. [1993], "Tests of Long-Run Purchasing Power Parity Using Alternative M ethodologies," Journal of M acroeconomics 15; pp. 109-22.

Greene, W. [1990], "M ultiple Roots of the Tobit Log-Likelihood," J ournal of Econometrics 39; pp. 365-80.

Iwata, S. [1993], "A N ote on M ultiple Roots of the Tobit Log Likelihood," Journal of E conometrics 42; pp. 441-46.

Kim, Y. [1990], "Purchasing Power Parity in the Long Run: A Cointegration Approach," Journal of M oney, Credit and Banking 22; pp. 491-503.

Nakatsuma, T., Uemura, J. and Tsurumi, H. [1997], A Point Optimal Unit Root Test, Mimeo.

Olsen, R. [1978], "N ote on the Uniqueness of the M aximum Likelihood Estimator of the Tobit M odel," Econometrica 46; pp. 1211-15.

Orme, C. [1989], "On the Uniqueness of the M aximum Likelihood Estimator in Truncated Regression M odels," Econometric Reviews 8; pp. 217-22.

Patel, J. [1990], "Purchasing Power Parity as a Long-Run Relation," Journal of Applied Econometrics 5; pp. 367-79.

Peristiani, S. [1994], "An Empirical Investigation of the Determinants of Discount Window Borrowing: A Desegregate Analysis," Journal of Bank ing and Finance 18(1); pp. 183-97.

Perron, P. and Vogelsang T. J. [1992], "N onstationarity and Level Shifts with an Application to Purchasing Power Parity," Journal of Business and 
Tanner, M .A. [1993], Tools for Statistical Inference, 2nd edition, N ew York: Springer-Verlag.

Taylor, M .P. [1990], "Ex Ante Purchasing Power Parity: Some Evidence Based on Vector Autoregessions in the Time Domain," Empirical Eco nomics 15(1); pp. 77-93.

Thisted, R.A. [1988], Elements of Statistical Computing: Numerical Computa tion, London: Chapman and Hall.

Tronzano, M . [ 1992], "Long-Run Purchasing Power Parity and M ean-Reversion in Real Exchange Rates: A Further Comment," Economia Interna zionale 45(1); pp. 77-100.

Tsurumi, H. and Wago, H. [1996], "A Bayesian Analysis of Unit Root and Cointegration with an Application to a Yen-Dollar Exchange Rate M odel," Advances in Econometrics 11(B); pp. 51-86.

\section{Appendix A \\ Chronological Summary of \\ the Centered Rate System and NT Dollar, 1978-1989 \\ Compiles from Central Bank Annual Reports, various issues}

\section{8-07-01}

1. A new foreign exchange policy was introduced. The fixed exchange rate system was changed to the centered rate system. The Exchange Rate Decision Committee was established consisting of one representative from the central bank and five members (presidents) of the five major banks.

2. The NT \$/ US\$ rate was appreciated from 38 to 36 .

\section{9-02-01}

1. The execution of the centered rate policy was formally started. 
2. The upper and lower bounds of the centered rate were relaxed.The central bank reports do not give the specific numbers for the bounds.

\section{1-08-12}

1. NT \$/ US\$ was depreciated from 36.24 to 38 .

2. The ranges of the centered rate were relaxed from $1 \%$ to $2.25 \%$

\section{2-09-01}

1. The centered rate was determined by taking the weighted average of inter bank transactions on the previous day. The transaction volumes were used as the weights.

2. The spot rate was restricted within $\pm N T \$ 0.1$ of the centered rate.

\section{4}

1. The spot rate was restricted within the $\pm 2.25 \%$ of the centered rate.

\section{6}

1. Due to the huge trade surpluses as well as to the difference between the domestic and foreign interest rates, the NT\$ appreciated from 39.85 to 35.50. (10\%appreciation).

\section{7}

1. The spot rate was relaxed to $\pm N T \$ 0.20$ of the centered rate. Cash transactions were relaxed to $\pm \mathrm{N} T \$ 0.40$.

\section{9-04-03}

1. The centered rate system was terminated. No more restrictions on the spot rate. However, various foreign exchange controls were still in effect.

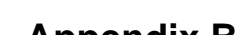


where $x_{t}$ is a $1 \times k$ vector of regressors, and $\beta$ is a $k \times 1$ vector of regression coefficients. $\left\{y_{t}\right\}$ is doubly truncated as:

$$
L_{t} \leq y_{t} \leq L_{u t}, \quad L_{t} \neq L_{u t}
$$

and that the error term $\left\{u_{t}\right\}$ follows an $\operatorname{ARM} A(1,1)$ process

$$
u_{t}=\frac{\Theta(B)}{\Phi(B)}{ }_{t}
$$

$\rho \beta \pi$

where $\varepsilon_{t} \sim N I D\left(0, \sigma^{2}\right), \Phi(B)=1-\phi_{1} B-\ldots-\phi_{p} B$, and $\Phi(B)=1+\theta_{1} B+\ldots \theta_{q} B$.

Since we often see that many economic time series follow a random walk, let us rewrite (4) as

$$
u_{t}=\frac{\Theta(B)}{(1-) \Phi_{1}(B)}
$$

where $\Phi_{1}(B)$ is the $p$ - 1-th order polynomial in B. Let us as ume that all the roots of $\Phi_{1}(B)$ and $\Theta(B)$ lie outside the unit circle. Then we may expand $\Phi_{1}(B) / \Theta(B)$ as

$$
\frac{\Phi_{1}(B)}{\Theta(B)}=1-{ }_{1} B-{ }_{2} B^{2}-
$$

and rewrite equation (3) as

$$
y_{t}-y_{t-1}=\left(x_{t}-x_{t-1}\right)+\frac{1}{1-{ }_{1} B-{ }_{2} B^{2}-} \quad t
$$

or

$$
y_{t}(\quad)=x_{t}()+{ }_{1} e_{t-1}()+{ }_{2} \mathrm{e}_{-2}()+{ }_{t}
$$

where $y_{t}()=y_{t}-y_{t-1}, \quad x_{t}()=x_{t}-x_{t-1}$, and

$$
e_{t-i}()=y_{t-i}()-x_{t-i}^{*}()^{*}, \quad i=1,2
$$

where $x_{*}^{*}:(0)=\left(x_{*} ;,(0), \ldots, x_{*} ; \iota(0)\right)$ is the $1 \times(k-1)$ vector of rearessors. 


$$
\mathrm{L}_{\mathrm{t}}-\mathrm{y}_{\mathrm{t}-1} \mathrm{x}_{\mathrm{t}}(\quad)-\sum_{\mathrm{i}=1}^{\mathrm{r}} \mathrm{e}_{\mathrm{t}-\mathrm{i}}(\mathrm{l})
$$

Divid- $\leq y_{t}()-x_{t}()-\sum_{i=1}^{r} e_{t-i}() \leq L_{t}-y_{t-1}-x_{t}()-\sum_{i=1}^{r} e_{t-i}()$.

i $\mathrm{n} \mathrm{g}$

both sides of the inequalities by $\sigma$ we have

$$
a_{t} \leq-t \leq a_{u t}
$$

where

$$
\begin{aligned}
& a_{t}=\frac{L_{t}-y_{t-1}-x_{t}()-\sum_{i=1}^{r} i e_{-i}()}{(n d} \\
& a_{u t}=\frac{L_{u t}-y_{t-1}-x_{t}()-\sum_{i=1}^{r} e_{t-i}()}{3} \pi 0
\end{aligned}
$$

$\beta \pi \sigma \rho$

The truncated normal distribution is modified to

$$
\frac{1}{\left.\Phi_{\mathrm{t}} /\right)_{\mathrm{ut}}-\Phi_{\mathrm{t}}}
$$

where

$$
\Phi_{u t} \int_{-\infty}^{a_{u t}}() d, \Phi_{t}=\int_{-\infty}^{a_{u t}}() d, \text { a n d }(a)=\frac{1}{\sqrt{2}} \exp \left(-\frac{1}{2} a^{2}\right)
$$

Let the prior pdf be given by

$$
p(,, \quad)=p(\mid,,) p(, \quad) \propto p(\mid)^{-1}
$$

where $\pi=\left(\pi_{1}, \ldots, \pi_{r}\right)$. Then the posterior pdf is

$\Gamma 7$


and the prior parameters $\beta_{0}$ and $\Sigma_{0}$ are generated by a bootstrap procedure. Rather than the bootstrap procedure let us set the prior pdf as

$$
p(\mid) \propto^{-1} \exp \left\{-\frac{1}{2^{2}}(1-10)^{2}\right\}
$$

where $\beta_{1}$ is the constant term. The reason why we use a proper prior only on the intercept term is that the trouble any Bayesian unit root inference faces is due to the fact that when $\rho=1$ the intercept term $\beta_{1}$ becomes un
identified. We follow the empirical Bayes procedure to determine the pridc parameter $\beta_{10}$ :

$$
\hat{10}_{10}=\max _{10} 0\left(\begin{array}{r}
10
\end{array}\right)
$$

where

$$
0=\int p(10,, \quad, \quad \text { data }) d d d .
$$

\section{$\eta \eta$}

$\partial \eta \partial \eta$

We may evaluate the integration by a numerical integration procedure, and here we use a Laplace approximation.

Let us first explain the Laplace approximation procedure to obtain the marginal posterior pdf as well as the posterior moments of a parameter of interest, $\eta_{1}$. The posterior pdf of $\eta_{1}$ is given by

$$
\mathrm{p}\left({ }_{1} \mid \text { data }\right) \propto\left|\Sigma^{*}\right| \mathrm{p}\left({ }_{1}, \hat{}_{2} \mid \text { data }\right)
$$

where $\eta_{2}$ is the vector of parameters we are not interested in, and

$$
\Sigma^{*}=\left[-\left.\frac{2 \ln p\left({ }_{1}, 2 \mid \text { data }\right)}{2}\right|_{2}\right]^{-1}
$$

and $\hat{\eta}_{2}$ maximizes the joint posterior pdf given $\eta_{1}$.

The nncterinr moment of $n(n$.$) is riven hy$ 


$$
E\left[g\left({ }_{1}\right)\right]=\frac{|\tilde{\Sigma}|^{1 / 2} \int\left(^{\sim}\right)}{\left.\left|\sum^{*}\right|^{1 / 2} p^{\prime}{ }_{1}{ }_{1}{ }_{2} \mid \text { data }\right)}
$$

where $\Sigma^{*}$ is the inverse of the negative of the Hessian evaluated at the posterior modal value $\hat{\eta}_{1}$ and $\hat{\eta}_{2} . \tilde{\Sigma}$ is the Hessian from $f(\eta)$ evaluated at $\tilde{\eta}=\arg$ $\max f(\eta)$. If $\Sigma^{*}$ and $\tilde{\Sigma}$ are positive definite, then the Laplace approximation works. However, there is no guarantee that they are always positive definite. In our model when $\rho$ is close to one (a unit root case) we see that $\Sigma^{*}$ and $\tilde{\Sigma}$ fail to be positive definite. Accordingly, let us first obtain the joint marginal posterior pdf of $\sigma$ and $\rho$ by the Laplace approximation method:

$$
p(, \quad \text { data }) \propto\left|-\frac{{ }^{2} \ln p(\text { data })}{"-1 / 2}\right|^{-12} p(, \quad, \mid \text { data })
$$

since

$$
\left[-\frac{{ }^{2} \ln p(\mid \text { data })}{"}\right]
$$

is uniformly positive definite where and $\eta=(\sigma, \rho, \theta)$ and $\theta=\left(\beta^{\prime}, \pi^{\prime}\right)^{\prime}$. From the approximate joint posterior pdf of $\sigma$ and $\rho$ we obtain the marginal posterior pdf of $\rho$ by

$$
p(\text { data }) \propto \int p(, \text { data }) d
$$

and we use a quadrature numerical integration procedure to integrate out $\sigma$. Similarly, from $p(\sigma, \rho \mid$ data $)$ we may obtain the marginal posterior pdf's of $\sigma$. The marginal posterior pdf of a regression coefficient $\beta_{\mathrm{i}}$ may be obtained by

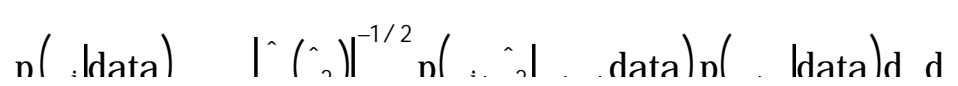

